\title{
Nanoscale
}

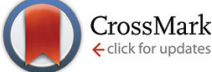

Cite this: Nanoscale, 2015, 7, 11267

Received 10th April 2015,

Accepted 28th May 2015

DOI: $10.1039 / c 5 n r 02300 a$

www.rsc.org/nanoscale

\section{Custom-shaped metal nanostructures based on DNA origami silhouettes $\uparrow$}

\author{
Boxuan Shen, $\star^{a}$ Veikko Linko, $t^{\mathrm{b}}$ Kosti Tapio, ${ }^{a}$ Mauri A. Kostiainen ${ }^{\star b}$ and \\ J. Jussi Toppari*a
}

The DNA origami technique provides an intriguing possibility to develop customized nanostructures for various bionanotechnological purposes. One target is to create tailored bottom-up-based plasmonic devices and metamaterials based on DNA metallization or controlled attachment of nanoparticles to the DNA designs. In this article, we demonstrate an alternative approach: DNA origami nanoshapes can be utilized in creating accurate, uniform and entirely metallic (e.g. gold, silver and copper) nanostructures on silicon substrates. The technique is based on developing silhouettes of the origamis in the grown silicon dioxide layer, and subsequently using this layer as a mask for further patterning. The proposed method has a high spatial resolution, and the fabrication yields can approach $90 \%$. The approach allows a cost-effective, parallel, large-scale patterning on a chip with fully tailored metallic nanostructures; the DNA origami shape and the applied metal can be specifically chosen for each conceivable implementation.

During the past three decades a great variety of different nanoscale objects have been constructed using DNA as a programmable building material. ${ }^{1,2}$ One of the most promising and robust methods for bottom-up fabrication with DNA is the socalled origami technique, ${ }^{3}$ which is based on folding a long single-stranded DNA scaffold into a desired shape with the help of a set of synthetic "staple" strands. It was originally designed for flat 2D single-layer structures, but since then the method has been generalized for partially double-layered tiles, ${ }^{4}$ hollow 3D objects, ${ }^{5}$ multilayer $3 \mathrm{D}$ origamis, ${ }^{6}$ and struc-

\footnotetext{
${ }^{a}$ University of Jyvaskyla, Department of Physics, Nanoscience Center, P.O. Box 35, FI-40014 University of Jyväskylä, Finland. E-mail: j.jussi.toppari@jyu.fi

${ }^{b}$ Biohybrid Materials, Department of Biotechnology and Chemical Technology, Aalto University, P.O. Box 16100, FI-00076 Aalto, Espoo, Finland.

E-mail: mauri.kostiainen@aalto.fi

$\dagger$ Electronic supplementary information (ESI) available: CanDo-simulated solution shape of a rectangular origami. Fabrication and purification of DNA origamis. Experimental details, instrumentation and fabrication procedures for metallic nanostructures. Statistics of the dimensions of the gold nanostructures. Additional SEM images of the gold nanostructures. See DOI: 10.1039/ c5nr02300a

$\$$ Equal contribution.
}

tures containing customized curvatures and twists. ${ }^{7,8}$ Lately, methods allowing 3D meshing of DNA structures ${ }^{9}$ and scaffold-free origamis ${ }^{10,11}$ have been demonstrated. The techniques include powerful software for designing ${ }^{12}$ and simulating $^{13-15}$ the shapes of the user-defined structures. These methods together form a versatile tool-kit for the designers. Recent progress in the field of structural DNA nanotechnology ${ }^{16,17}$ has yielded a plethora of intriguing bionanotechnological applications, such as artificial ion channels, ${ }^{18}$ nanoreactors, ${ }^{19}$ gatekeepers for nanopores ${ }^{20-22}$ and drug delivery vehicles. ${ }^{23-25}$

In addition to the aforementioned applications, the superior spatial addressability of the self-assembled DNA structures can be utilized in nanoscale patterning. Reliable nanoparticle patterning on the DNA architectures is a key feature for miniaturizing electronics ${ }^{26,27}$ and developing photonic metamaterials, ${ }^{28}$ as well as for novel plasmonic nanostructures and devices. ${ }^{29-31}$ The reported assemblies include various types of DNA scaffolds decorated with complex or chiral nanoparticle geometries ${ }^{32-35}$ and DNA-templated growth of metallic nanoshapes. ${ }^{36-38}$ Lately, hollow origamis have been used as "molds" for casting metal nanoparticles, i.e., for guiding the growth of the encapsulated metallic "seed" particles into the desired nanoshapes. ${ }^{39,40}$ Furthermore, single DNA molecules or structures can be directed and anchored to the selected areas of lithographically fabricated substrates in order to form desired patterns, ${ }^{41-49}$ or alternatively, the DNA objects can be directly tiled together into well-ordered largescale assemblies. ${ }^{4,50-52}$

In this communication, we expand the toolbox of bottomup-based methods by presenting a novel technique for creating uniform custom-shaped metallic nano-objects directly on the silicon chip by exploiting the high spatial accuracy of DNA origami nanoarchitectures (see Fig. 1). We believe that the method can readily open up new opportunities in nanolithographic sample fabrication aiming towards metamaterials and nanoplasmonics. Through further optimization, the technique could be generalized for other substrates, as well as for larger and more complex DNA-based assemblies. 
1.
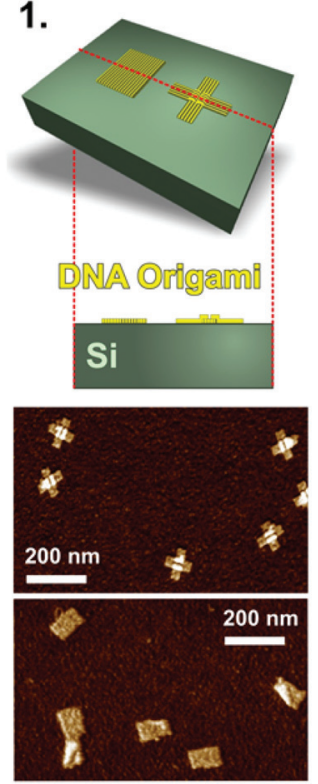

2.
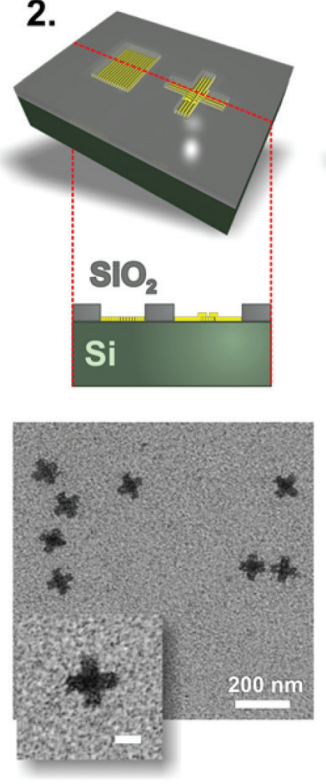

3.
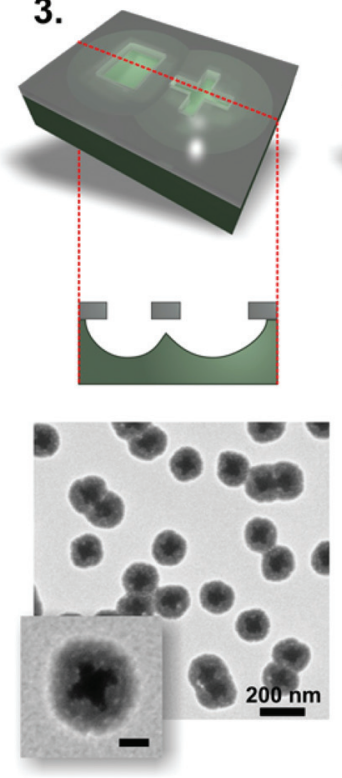

4.
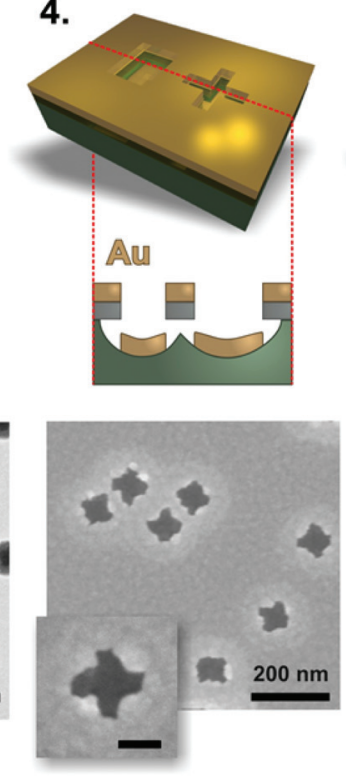

5.
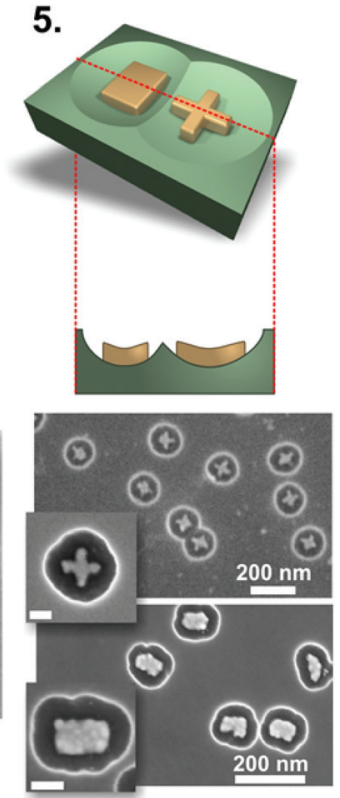

Fig. 1 Fabrication of gold nanostructures. Step 1: DNA origami structures ("Seeman tiles"4 (ST) and "Rothemund rectangles"3 (RR)) are deposited onto the silicon ( $\mathrm{Si}$ ) substrate. Note that due to the highly twisted shape of RR, some rectangles might appear slightly squeezed or rolled-up on the substrate. Step 2: Silicon dioxide $\left(\mathrm{SiO}_{2}\right)$ layer is grown in a chemical vapor deposition (CVD) process on the Si chip. The oxide layer grows selectively, and thus "DNA origami silhouettes" are created. Step 3: The "silhouettes" are used as the openings in etching of the silicon underneath the $\mathrm{SiO}_{2}$ layer. The reactive ion etched (RIE) wells in the silicon are clearly visible beneath the silhouettes. Step 4: Gold is deposited onto the chip using an ultra-high vacuum (UHV) electron beam evaporator. Step 5: The $\mathrm{SiO}_{2}$ layer (with the metal on top) is removed in a $\mathrm{HF}$ : $\mathrm{HCl}$-based lift-off procedure. This leaves the DNA origami-shaped gold nanostructures on the silicon chip. The scale bars in the insets are $50 \mathrm{~nm}$.

Briefly, our method relies on the selective growth of a thin silicon dioxide layer ${ }^{53}$ on top of the silicon substrate (with the native oxide) that supports the deposited DNA origami shapes (Fig. 1: steps 1 and 2). The $\mathrm{SiO}_{2}$ primarily grows on top of the silicon, and thus the process leaves the "DNA origami silhouettes" as openings in the formed $\mathrm{SiO}_{2}$ layer (step 2). The aforementioned layer can be used as a mask for plasma etching (RIE) the silicon beneath the opening (step 3). The procedure allows forming smooth and rounded wells in the silicon, which have the $\mathrm{SiO}_{2}$ window with the origami-shaped opening on the top (step 3). The origami silhouette can be subsequently used as a mask for depositing metal by evaporation onto the chip (step 4). Finally, the $\mathrm{SiO}_{2}$ layer can be removed by hydrofluoric acid ( $\mathrm{HF}$ ) and hydrochloride ( $\mathrm{HCl}$ )-based wet etching, leaving just the origami-shaped metallic nanostructures on the silicon chip (step 5).

We have demonstrated the fabrication of the metal nanoshapes using three different metals (gold, copper and silver) and two structurally different DNA objects: single-layer "Rothemund rectangle"3 (RR) (92 nm × $72 \mathrm{~nm}$ ) and partially double-layered cross-shaped "Seeman tile"4 (ST) (two $95 \mathrm{~nm} \times$ $30 \mathrm{~nm}$ layers crossing each other) (step 1, Fig. 1). The origami designs were fabricated in $1 \times$ TAE (40 mM Tris, $19 \mathrm{mM}$ acetic acid, $1 \mathrm{mM}$ EDTA) buffer with $12.5 \mathrm{mM} \mathrm{Mg}^{++}$using 5-20 nM scaffold strand concentration and $10 \times$ excess of staple strands (IDT). The side strands for both structures were left out in order to avoid blunt-end stacking of the objects. The annealing ramps for the folding of the structures are the same as reported previously. ${ }^{3,4}$ The quality of the folding was verified with agarose gel electrophoresis and AFM imaging (tapping mode, Veeco Dimension 3100). The structures can be optionally purified (excess amount of staple strands removed/buffer exchanged) by spin-filtering (see ESI $\dagger$ ). However, we observed that the purification step is not necessarily needed in the successful fabrication procedure.

For the substrate, we used a slightly boron-doped p-type silicon chip $(6 \times 6 \mathrm{~mm})$, which was cleaned with hot acetone and isopropanol followed by a brief sonication ( $2 \mathrm{~min}$ ) and a RIE-based (Oxford Plasmalab 80 Plus) oxygen plasma treatment (oxygen flow $50 \mathrm{sccm}$, plasma power $200 \mathrm{~W}$, temperature $30^{\circ} \mathrm{C}$ and time $20 \mathrm{~min}$ ). The plasma treatment was carried out in order to induce hydroxyl $(-\mathrm{OH})$ group formation on the silicon surface (negatively charged and hydrophilic substrate), and therefore to help immobilize DNA origami via $\mathrm{Mg}^{++}$ions. $5 \mu \mathrm{l}$ of DNA origami solution in $1 \times$ TAE buffer with $100 \mathrm{mM}$ $\mathrm{Mg}^{++}$was pipetted onto the silicon chip right after the plasma treatment. The sample was incubated in a closed chamber for 5 min, washed 3 times with $50 \mu$ of double-distilled (dd) $\mathrm{H}_{2} \mathrm{O}$ and finally gently dried under a $\mathrm{N}_{2}$ gas flow (step 1, Fig. 1).

The Si chip with the immobilized DNA origami structures was placed in a 1.5-liter glass desiccator for 16 hours together with two small glass vials containing tetraethyl orthosilicate (TEOS, $\geq 99.0 \%$, Sigma-Aldrich) and ammonium hydroxide $\left(\mathrm{NH}_{4} \mathrm{OH}, 25 \% \mathrm{NH}_{3}\right.$ in $\mathrm{H}_{2} \mathrm{O}$, Baker Analyzed). In addition, 
80 grams of silica gel, which was conditioned overnight in a humidity chamber (Weiss Climatic test chamber, 80\% relative humidity, room temperature), were positioned at the bottom of the desiccator in order to improve the quality of the grown silicon dioxide layer. The aforementioned chemical vapor deposition (CVD) treatment reliably created precise origami silhouettes in the $5-10 \mathrm{~nm}$ thick silicon dioxide layer (step 2, Fig. 1), since the oxide predominantly grows on the bare areas of the chip. ${ }^{53}$

The sample with the formed silhouettes was etched using RIE (step 3, Fig. 1). First, in order to expose the Si surface beneath the grown silicon dioxide layer (including the formed native oxide layer), 2-4 $\mathrm{nm}$ of $\mathrm{SiO}_{2}$ was etched away $\left(\mathrm{CHF}_{3}\right.$ flow $25 \mathrm{sccm}$, Ar flow $25 \mathrm{sccm}$, plasma power $100 \mathrm{~W}$, temperature $25^{\circ} \mathrm{C}$ and time 12-24 s). Subsequently, $57 \mathrm{~nm}$ of Si was etched $\left(\mathrm{SF}_{6}\right.$ flow $100 \mathrm{sccm}, \mathrm{O}_{2}$ flow $8 \mathrm{sccm}$, plasma power $50 \mathrm{~W}$, temperature $30{ }^{\circ} \mathrm{C}$ and time $30 \mathrm{~s}$ ) resulting in the rounded silicon wells beneath the $\mathrm{SiO}_{2}$ windows.

The following metal deposition (gold, copper or silver) was carried out using an electron beam evaporator (step 4, Fig. 1) in an ultra-high vacuum chamber (UHV). $20 \mathrm{~nm}$ of metal was perpendicularly evaporated onto the sample surface at a rate of $0.04 \mathrm{~nm} \mathrm{~s}^{-1}$ (for copper) or $0.06 \mathrm{~nm} \mathrm{~s}^{-1}$ (for gold and silver). After the metal deposition, the $\mathrm{SiO}_{2}$ mask together with the metal film on top of it was removed in a lift-off procedure using $\mathrm{HF}(38 \%) / \mathrm{HCl}(38 \%)(12: 1)$ solution for gold or $4 \% \mathrm{HF}$ in $\mathrm{H}_{2} \mathrm{O}$ for copper and silver. Finally, the sample was washed with $\mathrm{ddH}_{2} \mathrm{O}$ and dried under $\mathrm{N}_{2}$ flow (step 5 with gold structures is presented in Fig. 2 and 3).

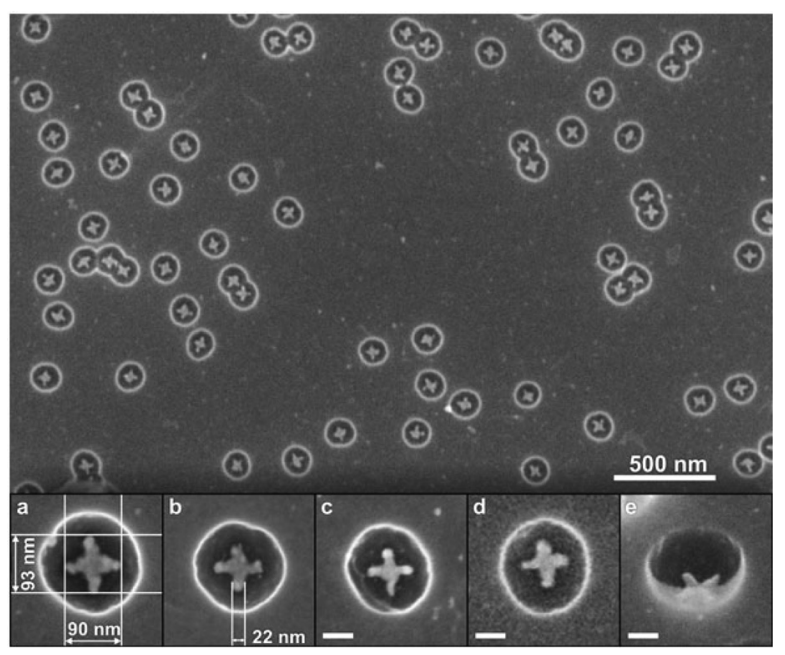

Fig. 2 Step 5 for ST origami. SEM image shows the high yield of patterning; $86 \pm 3 \%$ of all the observed particles are correctly formed metallic cross-like structures. Subfigures (a)-(d) show the close-up images of the typical well-formed gold nanostructures on the silicon chip. Subfigure (e) is a tilted SEM image of the metallic cross in the silicon well. The scale bars in (c)-(e) are $50 \mathrm{~nm}$. The dimensions of the gold nanostructures are slightly $(7-25 \%)$ smaller than the dimensions in the original DNA origami design.

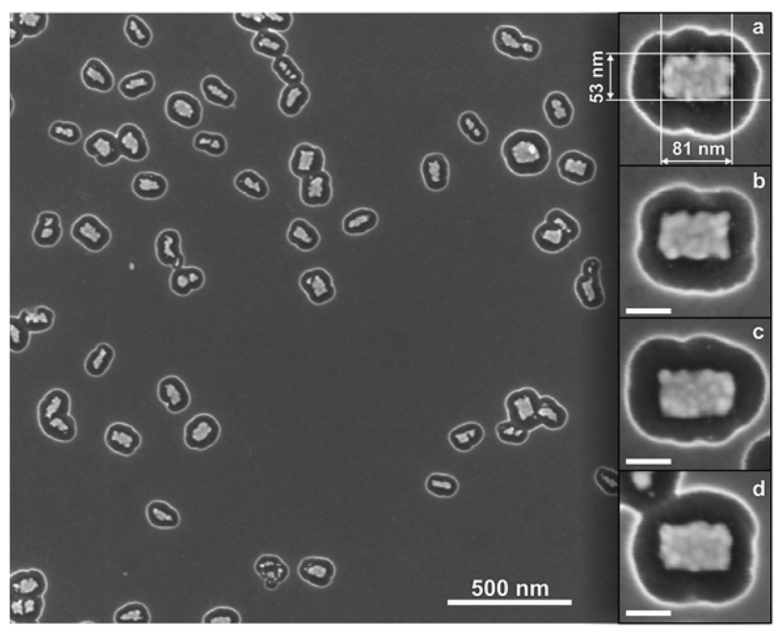

Fig. 3 Step 5 for RR origami. SEM image of the gold rectangular shapes on the Si substrate. The particle size distribution is much wider than in the ST case, which can be attributed to the highly twisted conformation of the RR structures in the Si chip. However, by taking this into account, the yield for the fabrication is acceptable: $65 \pm 2 \%$. Subfigures (a) $-(d)$ show the close-up images of the desired shapes. The scale bars are $50 \mathrm{~nm}$.

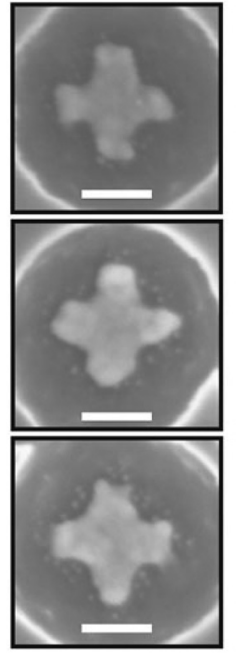

$\mathrm{Au}$

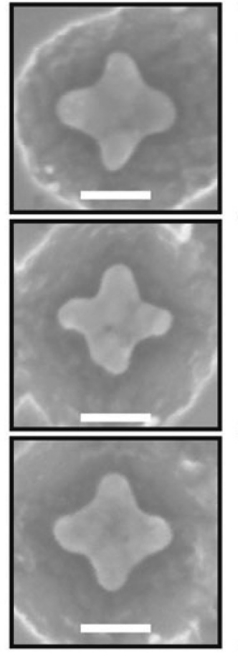

$\mathrm{Cu}$

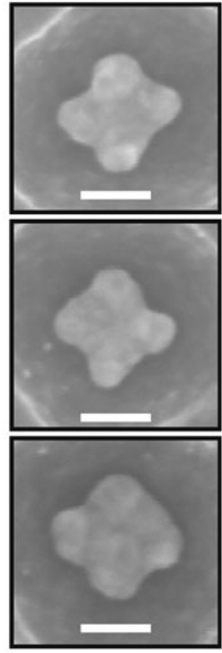

$\mathrm{Ag}$
Fig. 4 SEM images of the ST shapes made out of gold ( $\mathrm{Au})$, copper $(\mathrm{Cu})$ and silver (Ag). The scale bars are $50 \mathrm{~nm}$.

Fig. 4 shows the feasibility of the proposed fabrication method: it illustrates ST patterns made out of different metals, i.e. gold, copper and silver. It is noteworthy to mention that the shape of the metallic ST structure becomes slightly rounded in the case of silver and copper deposition due to the native oxidation of these metals. The ready samples were imaged with AFM (Veeco Dimension 3100) or SEM (Raith eLine). 
For ST-patterning (Fig. 2), $86 \pm 3 \%$ of all the observed particles were correctly formed metallic (gold) crosses, and the yield for the RR-based objects (Fig. 3) was $65 \pm 2 \%$ (see the ESI $\dagger$ for the details). The adopted solution shapes for both origamis are twisted to some extent (especially RR, see the ESI $\dagger$ ), but the twisted origamis can be straightened when they land onto the substrate. However, some structures do not adopt the desired orientation on the silicon substrate after their deposition, and thus the yield accordingly decreased. By choosing twist-corrected and more rigid origami structures for patterning one could presumably increase the success rate.

In addition, it was observed that RR-based gold nanostructures had an average width of $37 \pm 10 \mathrm{~nm}$ and an average length of $80 \pm 6 \mathrm{~nm}$ (see the ESI $\dagger$ for the statistics of the dimensions). For the gold ST-patterns the average length in both directions was $89 \pm 6 \mathrm{~nm}$ and the average width of the arm was $23 \pm 7 \mathrm{~nm}$. The length of ST-patterned metallic structures is close to the length of the origami (on average only $\sim 7 \%$ smaller), but the width is about $25 \%$ smaller compared to the original origami design. In the case of the RR-based metallic structures, the length corresponds to that of the origami structure ( $\sim 15 \%$ smaller), but the width is on average about $48 \%$ smaller than designed, mainly because the twisted RR origami tends to roll up around its longer axis on the silicon substrate. Moreover, there are two plausible explanations for the slightly reduced dimensions of the gold nanoshapes. One is that although the silicon dioxide layer mainly grows perpendicular to the $\mathrm{Si}$ substrate, it can also grow on the walls of the silhouettes, thus resulting in a decreased size of the opening. The other is that the evaporated gold may adhere or cluster onto the edges of the mask, which moderately reduces the size of the silhouettes. Nevertheless, the obtained yields indicate that the proposed technique is highly reproducible (additional SEM images of the gold nanostructures in the ESI $\dagger$ ).

\section{Conclusions}

As a conclusion, we report a novel high-throughput technique for fabricating uniform and tailored metallic nanostructures on a silicon chip. The fabrication method exploits the high spatial addressability of the tailored DNA nanostructures. We have demonstrated the feasibility and modularity of the technique by utilizing two structurally different scaffolded DNA origamis for creating the origami silhouettes, and three different metals for deposition (gold, copper and silver, Fig. 4). The advantage of the method is that, in principle, one can use any kind of origami shape (dimers, multimers and even larger arrays are equally accessible) and any metal that survives HF or $\mathrm{HF} / \mathrm{HCl}$ etching. However, the fabrication of large and complex structures might require more anisotropic etch profiles of silicon, which can be achieved by utilizing advanced lithographic techniques such as a deep reactive ion etching (DRIE)..$^{54}$
In general, one has to pay extra attention to the actual solution shape of the DNA origami in order to avoid non-uniform size distribution of the fabricated metal nanostructures. One intriguing possibility to increase the impact of the method would be to use scaffold-free origamis ${ }^{10,11}$ for fabricating any desired patterns in a cost-effective manner, i.e. by utilizing just one set of staple strands. We believe that our method could be equally extended to other substrates - such as sandwiched Sibased multilayered substrates - by completely removing the silicon layer once the metal pattern has been formed. The aforementioned approach could readily facilitate the fabrication on the transparent surfaces and thus the characterization of plasmonic properties of the created nanoshapes.

In contrast to previously reported DNA-templated metallic shapes, ${ }^{36-38}$ our method is easy, cost-effective and it allows uniform, regular and accurate structures. Compared to the recently reported innovative DNA mold approach, ${ }^{39,40}$ our method allows the use of a variety of metals and still it provides a similar patterning resolution. In addition, it might allow an easier route to fabricate specific nanoshapes or even larger origami-based arrays. However, our technique is substrate-based and thus, creating nanoparticles in a solutionphase is not accessible. Despite that, well-ordered large-scale parallel patterning could be realized e.g. by exploiting electric fields for directing the origami shapes on the chip, ${ }^{49}$ and subsequently transferring the created array to the target substrate. $^{55}$

To date, DNA- and substrate-based molecular lithography approaches have not fully contemplated the possibilities of fabricating metallic nanoshapes. Rather, previous studies cover either a positive- or negative-tone decoration of silicon and silicon oxide, ${ }^{53,56,57}$ or DNA-assisted graphene patterning. ${ }^{58}$ However, our straightforward method offers a novel and attractive way to combine bottom-up-based molecular selfassembly with standard top-down lithographic techniques. As a result, the proposed method facilitates the user-defined fabrication of metallic nanoshapes for a great variety of applications.

\section{Acknowledgements}

This work was supported by the Academy of Finland (grants 218182, 263526, 258309, 263504, 267497, 273645). In addition, V. L. and M. A. K. acknowledge financial support from Biocentrum Helsinki, Emil Aaltonen Foundation and EU EMRP (SIB61). This work was carried out under the Academy of Finland's Centres of Excellence Programme (2014-2019).

\section{Notes and references}

\author{
1 N. C. Seeman, J. Theor. Biol., 1982, 99, 237-247. \\ 2 N. C. Seeman, Nano Lett., 2010, 10, 1971-1978. \\ 3 P. W. K. Rothemund, Nature, 2006, 440, 297-302.
}


4 W. Liu, H. Zhong, R. Wang and N. C. Seeman, Angew. Chem., Int. Ed., 2011, 50, 264-267.

5 E. S. Andersen, M. Dong, M. M. Nielsen, K. Jahn, R. Subramani, W. Mamdouh, M. M. Golas, B. Sander, H. Stark, C. L. P. Oliveira, J. S. Pedersen, V. Birkedal, F. Besenbacher, K. V. Gothelf and J. Kjems, Nature, 2009, 459, 73-76.

6 S. M. Douglas, H. Dietz, T. Liedl, B. Högberg, F. Graf and W. M. Shih, Nature, 2009, 459, 414-418.

7 H. Dietz, S. M. Douglas and W. M. Shih, Science, 2009, 325, 725-730.

8 D. Han, S. Pal, J. Nangreave, Z. Deng, Y. Liu and H. Yan, Science, 2011, 332, 342-346.

9 D. Han, S. Pal, Y. Yang, S. Jiang, J. Nangreave, Y. Liu and H. Yan, Science, 2013, 339, 1412-1415.

10 B. Wei, M. Dai and P. Yin, Nature, 2012, 485, 623626.

11 Y. Ke, L. L. Ong, W. M. Shih and P. Yin, Science, 2012, 338, 1177-1183.

12 S. M. Douglas, A. H. Marblestone, S. Teerapittayanon, A. Vazquez, G. M. Church and W. M. Shih, Nucleic Acids Res., 2009, 37, 5001-5006.

13 C. E. Castro, F. Kilchherr, D.-N. Kim, E. L. Shiao, T. Wauer, P. Wortmann, M. Bathe and H. Dietz, Nat. Methods, 2011, 8, 221-229.

14 D.-N. Kim, F. Kilchherr, H. Dietz and M. Bathe, Nucleic Acids Res., 2012, 40, 2862-2868.

15 K. Pan, D.-N. Kim, F. Zhang, M. R. Adendorff, H. Yan and M. Bathe, Nat. Commun., 2014, 5, 5578.

16 V. Linko and H. Dietz, Curr. Opin. Biotechnol., 2013, 24, 555-561.

17 F. Zhang, J. Nangreave, Y. Liu and H. Yan, J. Am. Chem. Soc., 2014, 136, 11198-11211.

18 M. Langecker, V. Arnaut, T. G. Martin, J. List, S. Renner, M. Mayer, H. Dietz and F. C. Simmel, Science, 2012, 338, 932-936.

19 V. Linko, M. Eerikäinen and M. A. Kostiainen, Chem. Commun., 2015, 51, 5351-5354.

20 N. A. W. Bell, C. R. Engst, M. Ablay, G. Divitini, C. Ducati, T. Liedl and U. F. Keyser, Nano Lett., 2012, 12, 512-517.

21 R. Wei, T. G. Martin, U. Rant and H. Dietz, Angew. Chem., Int. Ed., 2012, 51, 4864-4867.

22 C. Plesa, A. N. Ananth, V. Linko, C. Gülcher, A. J. Katan, H. Dietz and C. Dekker, ACS Nano, 2014, 8, 35-43.

23 S. M. Douglas, I. Bachelet and G. M. Church, Science, 2012, 335, 831-834.

24 J. Mikkilä, A.-P. Eskelinen, E. H. Niemelä, V. Linko, M. J. Frilander, P. Törmä and M. A. Kostiainen, Nano Lett., 2014, 14, 2196-2200.

25 S. D. Perrault and W. M. Shih, ACS Nano, 2014, 8, 51325140.

26 H. T. Maune, S.-P. Han, R. D. Barish, M. Bockrath, W. A. Goddard III, P. W. K. Rothemund and E. Winfree, Nat. Nanotechnol., 2010, 5, 61-66.

27 V. Linko and J. J. Toppari, J. Self-Assem. Mol. Electron., 2013, 1, 101-124.
28 C. M. Soukoulis and M. Wegener, Nat. Photonics, 2011, 5, 523-530.

29 M. R. Jones, K. D. Osberg, R. J. Macfarlane, M. R. Langille and C. A. Mirkin, Chem. Rev., 2011, 111, 3736-3827.

30 S. J. Tan, M. J. Campolongo, D. Luo and W. Cheng, Nat. Nanotechnol., 2011, 6, 268-276.

31 J. Chao, Y. Lin, H. Liu, L. Wang and C. Fan, Mater. Today, 2015, DOI: 10.1016/j.mattod.2015.01.018.

32 J. Sharma, R. Chhabra, C. S. Andersen, K. V. Gothelf, H. Yan and Y. Liu, J. Am. Chem. Soc., 2008, 130, 7820-7821.

33 A. J. Mastroianni, S. A. Claridge and A. P. Alivisatos, J. Am. Chem. Soc., 2009, 131, 8455-8459.

34 A. Kuzyk, R. Schreiber, Z. Fan, G. Pardatscher, E.-M. Roller, A. Högele, F. C. Simmel, A. O. Govorov and T. Liedl, Nature, 2012, 483, 311-314.

35 E.-M. Roller, L. K. Khorashad, M. Fedoruk, R. Schreiber, A. O. Govorov and T. Liedl, Nano Lett., 2015, 15, 1368-1373.

36 M. Pilo-Pais, S. Goldberg, E. Samano, T. H. LaBean and G. Finkelstein, Nano Lett., 2011, 11, 3489-3492.

37 R. Schreiber, S. Kempter, S. Höller, V. Schüller, D. Schiffels, S. S. Simmel, P. C. Nickels and T. Liedl, Small, 2011, 7, 1795-1799.

38 J. Liu, Y. Geng, E. Pound, S. Gyawali, J. R. Ashton, J. Hickey, A. T. Woolley and J. N. Harb, ACS Nano, 2011, 5, 2240-2247.

39 S. Helmi, C. Ziegler, D. J. Kauert and R. Seidel, Nano Lett., 2014, 14, 6693-6698.

40 W. Sun, E. Boulais, Y. Hakobyan, W. L. Wang, A. Guan, M. Bathe and P. Yin, Science, 2014, 346, 1258361.

41 A. Kuzyk, B. Yurke, J. J. Toppari, V. Linko and P. Törmä, Small, 2008, 4, 447-450.

42 A. E. Gerdon, S. S. Oh, K. Hsieh, Y. Ke, H. Yan and H. T. Soh, Small, 2009, 5, 1942-1946.

43 R. J. Kershner, L. D. Bozano, C. M. Micheel, A. M. Hung, A. R. Fornof, J. N. Cha, C. T. Rettner, M. Bersani, J. Frommer, P. W. K. Rothemund and G. M. Wallraff, Nat. Nanotechnol., 2009, 4, 557-561.

44 V. Linko, S.-T. Paasonen, A. Kuzyk, P. Törmä and J. J. Toppari, Small, 2009, 5, 2382-2386.

45 A. M. Hung, C. M. Micheel, L. D. Bozano, L. W. Osterbur, G. M. Wallraff and J. N. Cha, Nat. Nanotechnol., 2010, 5, 121-126.

46 V. Linko, J. Leppiniemi, B. Shen, E. Niskanen, V. P. Hytönen and J. J. Toppari, Nanoscale, 2011, 3, 37883792.

47 V. Linko, J. Leppiniemi, S.-T. Paasonen, V. P. Hytönen and J. J. Toppari, Nanotechnology, 2011, 22, 275610.

48 A. Gopinath and P. W. K. Rothemund, ACS Nano, 2014, 8, 12030-12040.

49 B. Shen, V. Linko, H. Dietz and J. J. Toppari, Electrophoresis, 2015, 36, 255-262.

50 A. A. Rafat, T. Pirzer, M. B. Scheible, A. Kostina and F. C. Simmel, Angew. Chem., Int. Ed., 2014, 53, 7665-7668.

51 S. Woo and P. W. K. Rothemund, Nat. Commun., 2014, 5, 4889.

52 Y. Ke, L. L. Ong, W. Sun, J. Song, M. Dong, W. M. Shih and P. Yin, Nat. Chem., 2014, 6, 994-1002. 
53 S. P. Surwade, F. Zhou, B. Wei, W. Sun, A. Powell, C. O'Donnell, P. Yin and H. Liu, J. Am. Chem. Soc., 2013, 135, 6778-6781.

54 F. Marty, L. Rousseau, B. Saadany, B. Mercier, O. Français, Y. Mita and T. Bourouina, Microelectron. J., 2005, 36, 673677.

55 T. K. Hakala, V. Linko, A.-P. Eskelinen, J. J. Toppari, A. Kuzyk and P. Törmä, Small, 2009, 5, 2683-2686.
56 S. P. Surwade, S. Zhao and H. Liu, J. Am. Chem. Soc., 2011, 133, 11868-11871.

57 F. Zhou, B. Michael, S. P. Surwade, K. B. Ricardo, S. Zhao and H. Liu, Chem. Mater., 2015, 27, 16921698.

58 Z. Jin, W. Sun, Y. Ke, C. J. Shih, G. L. C. Paulus, Q. H. Wang, B. Mu, P. Yin and M. S. Strano, Nat. Commun., 2013, 4, 1663. 